\title{
Humanizing the intensive care unit experience in a comprehensive cancer center: A patient- and family-centered improvement study
}

\section{Original Article \\ *These authors equally contributed to this work.}

Cite this article: Cuenca JA et al. (2022). Humanizing the intensive care unit experience in a comprehensive cancer center: A patientand family-centered improvement study. Palliative and Supportive Care 20, 794-800. https://doi.org/10.1017/S1478951521001838

Received: 3 May 2021

Revised: 2 September 2021

Accepted: 31 October 2021

\section{Key words:}

Critical care; Family-centered care; Family engagement; Intensive care unit; Quality improvement

\section{Corresponding author:}

Olakunle Idowu,

Department of Critical Care Medicine, Division of Anesthesiology, Critical Care, and Pain Medicine, The University of Texas MD Anderson Cancer Center, 1515 Holcombe Blvd, Unit 112 Houston, TX 77030, USA.

E-mail: oldowu@mdanderson.org
(C) The Author(s), 2021. Published by Cambridge University Press. This is an Open Access article, distributed under the terms of the Creative Commons Attribution licence (http://creativecommons.org/licenses/by/4.0/), which permits unrestricted re-use, distribution and reproduction, provided the original article is properly cited.

\section{CAMBRIDGE} UNIVERSITY PRESS

\author{
John A. Cuenca, M.D. ${ }^{*}$ (D), Nirmala Manjappachar, M.D. ${ }^{*}$, Joel Nates, B.S., \\ Tiffany Mundie, D.N.P., Lisa Beil, M.S.N., Eric Christensen, M.D., Peyton Martin, B.S. (D), \\ Nancy Diaz, B.S., Lorraine S. Layton, M.S.N., Karen Plexman, M.S.N., \\ Joseph L. Nates, M.D., Kristen J. Price, M.D. and Olakunle Idowu, M.D.
}

Department of Critical Care Medicine, Division of Anesthesiology, Critical Care, and Pain Medicine, The University of Texas MD Anderson Cancer Center, Houston, TX

\begin{abstract}
Objectives. Improving family-centered outcomes is a priority in oncologic critical care. As part of the Intensive Care Unit (ICU) Patient-Centered Outcomes Research Collaborative, we implemented patient- and family-centered initiatives in a comprehensive cancer center. Methods. A multidisciplinary team was created to implement the initiatives. We instituted an open visitation policy (OVP) that revamped the use of the two-way communication boards and enhanced the waiting room experience by hosting ICU family-centered events. To assess the initiatives' effects, we carried out pre-intervention (PRE) and post-intervention (POST) family/caregiver and ICU practitioner surveys.

Results. A total of $159(\mathrm{PRE}=79, \mathrm{POST}=80)$ family members and $147(\mathrm{PRE}=95, \mathrm{POST}=52)$ ICU practitioners participated. Regarding the decision-making process, family members felt more included $(40.5 \%$ vs. $68.8 \%, p<0.001)$ and more supported $(29.1 \%$ vs. $48.8 \%, p=0.011)$ after the implementation of the initiatives. The caregivers also felt more control over the decision-making process in the POST survey $(34.2 \%$ vs. $56.3 \%, p=0.005)$. Although $33 \%$ of the ICU staff considered OVP was beneficial for the ICU, $41 \%$ disagreed and $26 \%$ were neutral. Only half of them responded that OVP was beneficial for patients and 63\% agreed that OVP was beneficial for families. Half of the practitioners agreed that OVP resulted in additional work for staff. Significance of results. Our project effectively promoted patient- and family-centered care. The families expressed satisfaction with the communication of information and the decision-making process. However, the ICU staff felt that the initiatives increased their work load. Further research is needed to understand whether making this project universal or introducing additional novel practices would significantly benefit patients admitted to the ICU and their family.
\end{abstract}

\section{Introduction}

Caregivers of cancer patients suffer a profound impact on their well-being and quality of life (Girgis et al., 2013; Sun et al., 2019). Their emotional burden worsens when their loved one is hospitalized and requires an intensive care unit (ICU) admission. Moreover, as the cancer population is at high risk of developing life-threatening events that require intensive care treatment (Wallace et al., 2016; Gutierrez et al., 2018; Cuenca et al., 2020), developing and enacting better family-centered care strategies for critically ill cancer patients is paramount. Increasing family engagement has been associated with a shorter ICU stay (Lee et al., 2019), decreased cardiocirculatory complications (Fumagalli et al., 2006), and reduced patient falls (Dupree et al., 2014) without increasing infection rates or adverse events (Adams et al., 2011; Bishop et al., 2013).

Historically, ICUs have maintained strict policies about visitation and family-centered care (Liu et al., 2013). However, the belief that patients in the ICU benefit from restricted visitation has been contradicted by evidence that social isolation can increase morbidity and mortality (Cacioppo et al., 2011). The COVID-19 pandemic has highlighted the various deleterious psychological effects that prohibiting visitation can generate in patients, families, and healthcare providers (Azoulay et al., 2021). The Guidelines for Family-Centered Care in the Neonatal, Pediatric, and Adult ICU suggest that family members of critically ill patients be "offered open or flexible family presence at the bedside" (Davidson et al., 2017). Despite this, hospitals' visitation policies in their ICUs still vary widely (Liu et al., 2013). Strict visitation policies cause the families to stay mainly in the ICU waiting room, making them feel less engaged with the care of their loved ones (Davidson et al., 2017). For these reasons, waiting rooms should be a place of comfort with nearby restrooms and places to eat, and should post easily read signage to help family members navigate around (Deitrick et al., 2005; Karlsson et al., 2011). 
To enhance the ICU family engagement and overall satisfaction of care by patients and their families, we participated in a national performance improvement study called the PatientCentered Outcomes Research (PCOR) Collaborative (Kleinpell et al., 2019). We implemented multilevel patient- and familycentered initiatives that were focused on (1) applying an open visitation policy (OVP), (2) using daily two-way communication boards, and (3) enhancing the ICU waiting room experience. Here, we report the perspectives of both the families and the ICU practitioners on these performance improvement initiatives.

\section{Methods}

\section{Study design and setting}

This "before and after" performance improvement multilevel intervention study was approved by the Qualitative Institutional Review Board and was conducted in the 34-bed medical and 18-bed surgical ICUs at the University of Texas MD Anderson Cancer Center. A multidisciplinary workgroup consisting of physicians, nurses, advanced practice providers, pharmacists, physical therapists, occupational therapists, dieticians, patient educators, patient advocates, chaplains, social workers, ethicists, and volunteer services was formed. The workgroup was involved in planning, addressing concerns, enabling information dissemination, and implementing patient- and family-centered care initiatives. In order to achieve a substantial improvement in family-centered care, the team decided to execute multiple initiatives simultaneously in a multilevel fashion.

To be considered eligible to participate in the study, respondents must have been caregivers of a patient admitted to the ICU or a healthcare provider who primarily worked in the ICU. We conducted pre-intervention (PRE) and the post-intervention (POST) surveys for families of patients admitted to the ICU and for ICU practitioners. The PRE surveys were carried out 1 month before the implementation period. At the same time, the institution renovated the ICUs and waiting rooms following the SCCM ICU design guidelines (Thompson et al., 2012). After a 6-month implementation period, the POST surveys were conducted. Consequently, there were two separate groups of family members who responded to the surveys (Figure 1). Potential participants were approached by the research team, only those who were willing to participate in the study were offered the links to the survey. The web secure database REDCap was used to anonymously collect and store all the survey data.

\section{Initiatives}

\section{Open visitation policy}

A visitor pass system was implemented that allowed each family to have two passes to the ICU. One was a 24 -h pass, allowing one family member to stay in the patient's room at any time during the day or night. The second pass allowed a second family member to be in the patient's room between 10:00 AM and 10:00 PM.

\section{Two-way communication boards}

We implemented this initiative early to optimize communication between patients, families, and caregivers. Daily goals were established for every patient during multidisciplinary rounds in the morning. Nurses updated the daily goals board with a minimum of two to three goals to be accomplished for the day, and subsequently, with a multidisciplinary approach, the ICU team addressed the goals with patients and families. Audits were performed daily to identify and overcome potential barriers. Patients and families were encouraged to write questions or concerns to the ICU team on the board.

\section{Enhanced waiting room experience}

We worked with volunteer services to provide therapeutic coloring books and daily coffee services to the waiting room. A comprehensive calendar was created to inform that family members of events could participate in free of charge. We held events such as ICU family celebrations, card-making sessions, and holiday music therapy sessions directed by a certified music therapist. The calendar also included MD Anderson's Integrative Medicine Program events such as yoga meditation, drumming sessions, Tai Chi, group singing, and cooking lessons.

\section{Surveys}

The PCOR collaborative leadership provided the surveys for this study (Kleinpell et al., 2019). The family/caregiver participants'

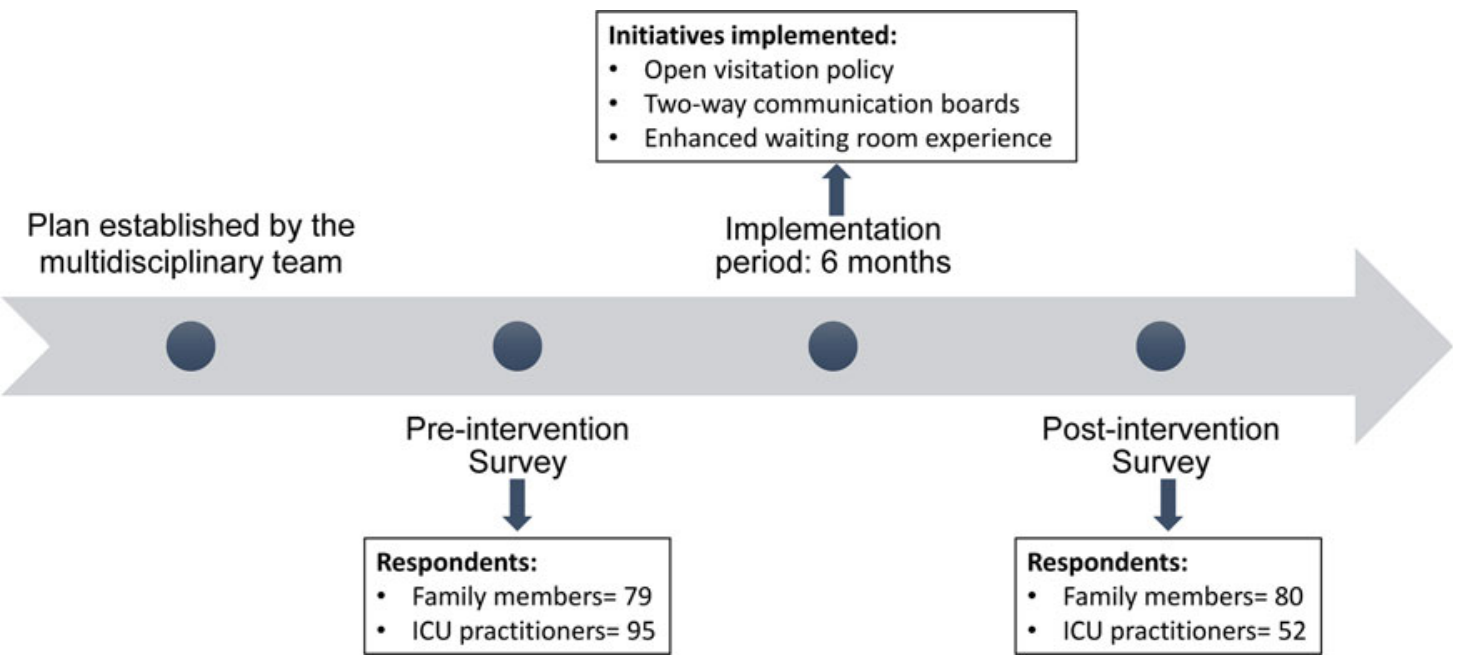

Fig. 1. Study schema. 
surveys were based on the Family Satisfaction with Care in the ICU Survey (Wall et al., 2007), which has well-established reliability and validity (Kleinpell et al., 2019). The questions addressed demographic information, staff competence, treatment of family, communication, waiting area environment, and overall family satisfaction. The ICU practitioners responded to the Patient- and Family-Centered Adult Intensive Care: A Self-Assessment Inventory (A Self-Assessment Inventory, 2019). The questions inquired about demographics such as age, sex, ICU practitioner role, years of practice, experience in the ICU, personal and professional experience with family presence, and family-centered care integration. Additionally, both the caregivers' and practitioners' POST surveys also included specific questions evaluating the implemented local initiatives (Kleinpell et al., 2019). All surveys were based on a Likert scale.

\section{Statistical analysis}

Descriptive analyses were performed for patients' family and ICU practitioner demographics and responses. For categorical variables, counts and frequencies were reported. Frequencies were calculated based on the non-missing values. For continuous variables, mean and standard deviation were reported. Differences between the PRE and POST intervention surveys were calculated using the $\mathrm{X}^{2}$ test. All statistical analyses were performed using the statistical software IBM SPPS Statistics for Windows, version 25 (SPSS Inc., Chicago, IL, USA).

\section{Results}

A total of $159(\mathrm{PRE}=79$ and POST $=80)$ family members completed the surveys. Table 1 describes the demographics and basic information of the participants. The families'/caregivers' roles included daughter $(21 \%)$, wife $(17 \%)$, son $(13 \%)$, parent $(8 \%)$, and husband (5\%). "Others" involved extended family members (partner, brother, sister, and other) (18\%). Almost half of the caregivers (50.9\%) had previous experience caring for a family member in the ICU. Approximately $42 \%$ of the caregivers lived with the patients. A total of $147 \quad(\mathrm{PRE}=95$ and POST $=52)$ ICU practitioners participated in the surveys. Most of them were nurses $(43 \%)$, followed by advanced practice providers (12\%), clinical pharmacists (12\%), physicians (9\%), respiratory therapists (9\%), and others such as occupational therapists, speech therapists, and dieticians (15\%).

\section{Family members' perspectives}

Overall, in the 159 caregivers (PRE and POST combined), the "excellent" to "very good" response for "ease of getting information" was $72 \%$. The "fair" to "poor" response was $8 \%$. The "excellent" to "very good" responses for "understanding of information" were $74 \%$ and the "fair" to "poor" responses were $5 \%$. Regarding their understanding of information, $74 \%$ of the participants rated it as "excellent" or "very good" and just 5\% considered it "fair" or "poor". About $73 \%$ of caregivers responded "excellent" to "very good" with regard to the "completeness of information," indicating that most family members were satisfied with how well the information regarding their loved ones was conveyed to them by the care team. A much lower percentage of respondents (8\%) reported that "completeness of information" was "fair" to "poor." Most (71\%) of the families were satisfied with the "consistency of information," indicating that they received similar
Table 1. Demographics and basic information of the participants

\begin{tabular}{|c|c|c|c|c|}
\hline Family members & $\begin{array}{c}\text { PRE } \\
N=79\end{array}$ & $\%$ & $\begin{array}{l}\text { POST } \\
N=80\end{array}$ & $\%$ \\
\hline Age (years), Mean (SD) & 47.98 & $( \pm 15.23)$ & 47.1 & $( \pm 14.86)$ \\
\hline \multicolumn{5}{|l|}{ Sex } \\
\hline Female & 54 & 68.35 & 48 & 60 \\
\hline Male & 25 & 31.65 & 32 & 40 \\
\hline \multicolumn{5}{|l|}{ Relationship to patient } \\
\hline Husband & 6 & 7.59 & 3 & 3.75 \\
\hline Wife & 21 & 26.58 & 6 & 7.5 \\
\hline Partner & 1 & 1.27 & 1 & 1.25 \\
\hline Brother & 5 & 6.33 & 9 & 11.25 \\
\hline Sister & 4 & 5.06 & 8 & 10 \\
\hline Daughter & 16 & 20.25 & 18 & 22.5 \\
\hline Son & 8 & 10.13 & 12 & 15 \\
\hline Father & 3 & 3.80 & 0 & 0 \\
\hline Mother & 4 & 5.06 & 6 & 7.5 \\
\hline Other & 11 & 13.92 & 17 & 21.25 \\
\hline
\end{tabular}

Before this most recent event, have you been involved as a family member of a patient in an ICU?

\begin{tabular}{ccccc}
\hline Yes & 45 & 56.96 & 36 & 45 \\
\hline No & 34 & 43.04 & 44 & 55 \\
\hline Do you live with the patient? & & & & \\
\hline Yes & 38 & 48.1 & 28 & 35 \\
\hline No & 41 & 51.9 & 52 & 65 \\
\hline & PRE & & POST \\
ICU practitioners & $N=95$ & $\%$ & $N=52$ & $\%$ \\
\hline
\end{tabular}

$\begin{array}{lllll}\text { Age in years, Mean (SD) } & 38.86 & ( \pm 10.54) & 41.13 & ( \pm 12.10)\end{array}$

Sex

\begin{tabular}{lcccc}
\hline Female & 74 & 77.89 & 37 & 71.15 \\
\hline Male & 13 & 13.68 & 9 & 17.31 \\
\hline Prefer not to answer & 8 & 8.42 & 6 & 11.54 \\
\hline
\end{tabular}

Clinical role

\begin{tabular}{lcccr}
\hline Advanced practice nurse & 6 & 6.45 & 7 & 13.21 \\
\hline Nurse & 40 & 43.01 & 28 & 52.83 \\
\hline Clinical pharmacist & 11 & 11.83 & 3 & 5.66 \\
\hline Physician & 8 & 8.6 & 9 & 16.98 \\
\hline Physician assistant & 5 & 5.38 & 1 & 1.89 \\
\hline Occupational therapist & 8 & 8.60 & 1 & 1.89 \\
\hline Other & 17 & 16.13 & 3 & 7.55 \\
\hline $\begin{array}{l}\text { Total years working in an ICU } \\
\text { setting, Mean (SD) }\end{array}$ & 9.28 & $( \pm 8.08)$ & 10.73 & $( \pm 7.25)$ \\
\hline $\begin{array}{l}\text { Years working in the current ICU, } \\
\text { Mean (SD) }\end{array}$ & 6.06 & $( \pm 5.67)$ & 6.8 & $( \pm 5.46)$ \\
\hline
\end{tabular}

ICU, intensive care unit.

messages from doctors and nurses, etc. A very small portion of relatives (9\%) responded "fair" to "poor." About 59\% of families responded "excellent" to "very good" about the "frequency with 
which ICU doctors communicated information." A few families (15\%) felt less satisfied, responding "fair" to "poor." The "excellent" to "good" response for family care and concern by ICU staff was $91 \%$. The responses of the family members by PRE and POST are summarized in Table 2;. Overall, the "excellent" response rate increased from PRE to POST; however, none of the improvements were statistically significant.

Most of the relatives (80\%) felt included in the decisionmaking process ("very" 55\%, "somewhat included" 25\%). Fewer relatives felt excluded (9\%). There was a statistically significant increase in the rate of "very included" in the decision-making process from the PRE to POST $(p<0.001)$. A considerable number (78\%) felt supported during the process, whereas $8 \%$ felt totally or somewhat overwhelmed. A significantly higher rate of participants felt very supported $(p=0.011)$ after the implementation of the initiatives. About half (45\%) of the relatives believed that they had good control of the process, whereas $30 \%$ felt less in control, and just $9 \%$ felt that the process was somewhat or completely out of their control. The proportion of respondents who felt in control of the process in the POST survey was higher than in the PRE survey $(p=0.005)$. About $13 \%$ of the caregivers believed that they needed more time to make decisions or to discuss or address their concerns.

Caregivers' perspectives regarding the ICU waiting room areas, OVP, and daily goal boards are presented in Supplementary Table 1. Among the 159 caregivers (PRE and POST combined) who responded to the survey, $71 \%$ considered their satisfaction with the ICU waiting area environment to be "excellent" or "very good". Most respondents described access to the kitchen (69\%), nutritious snacks (75\%), and laundry facilities (77\%) as "very well" to "ok." Regarding access to place for prayer or reflection, the majority (95\%) reported "very well" to "ok" responses. Overall, the "excellent" and "very well" responses rate increased from PRE to POST; however, only access to kitchen facilities $(p<0.001)$ and nutritious snacks $(p=0.008)$ were statistically significant. In the POST survey, the families evaluated the OVP and daily board goals. Over half of the respondents knew that the visitation policies had relaxed recently $(60.7 \%)$, most of them were satisfied with the OVP (89\%) and believed that the OVP was helpful for them and their loved ones (87.6\%). Likewise, the majority of the participants $(77.4 \%)$ were aware of the use of the daily goal boards, liked it (81.9\%), and agreed that it was helpful for them and their loved ones (81.9\%).

\section{ICU practitioners' perspectives}

The ICU practitioners' perspectives regarding the initiatives are presented in Table 3. Among the 147 respondents (PRE and POST combined), $38 \%$ preferred an OVP in the ICU, whereas $42 \%$ were in disagreement, and $19 \%$ were neutral. Regarding communication with family, $42 \%$ of providers believed that the OVP improved it, while $31 \%$ disagreed. Almost a quarter of the practitioners $(23 \%)$ thought that patient care was improved with OVP, whereas $37 \%$ disagreed and $40 \%$ were neutral. Although $33 \%$ responded that OVP was beneficial for the ICU, $41 \%$ disagreed and $26 \%$ were neutral. In addition, half of them responded that OVP was beneficial for patients, whereas $29 \%$ disagreed and $21 \%$ were neutral. Most (63\%) practitioners agreed that OVP was beneficial for families despite over half of them (51\%), believing that it could result in additional work for staff.

The use of the two-way communication boards was supported by $70 \%$ of the 147 responders, $26 \%$ were neutral, and only $4 \%$ were in disagreement. While almost half of the ICU practitioners
Table 2. Family members' perspectives on information dissemination and decision-making process

\begin{tabular}{|c|c|c|c|c|}
\hline & $\begin{array}{c}\text { PRE } \\
N=79\end{array}$ & $\%$ & $\begin{array}{l}\text { POST } \\
N=80\end{array}$ & $\%$ \\
\hline \multicolumn{5}{|c|}{ Ease of getting information } \\
\hline Excellent & 31 & 39.2 & 38 & 48.7 \\
\hline Very good & 25 & 31.6 & 19 & 24.4 \\
\hline Good & 14 & 17.7 & 17 & 21.8 \\
\hline Fair & 8 & 10.1 & 3 & 3.8 \\
\hline Poor & 1 & 1.3 & 1 & 1.3 \\
\hline $\mathrm{N} / \mathrm{A}$ & 0 & - & 2 & - \\
\hline \multicolumn{5}{|c|}{ Understanding of information } \\
\hline Excellent & 33 & 41.8 & 37 & 47.4 \\
\hline Very good & 27 & 34.2 & 19 & 24.4 \\
\hline Good & 15 & 19 & 18 & 23.1 \\
\hline Fair & 4 & 5.1 & 3 & 3.8 \\
\hline Poor & 0 & 0 & 1 & 1.3 \\
\hline N/A & 0 & - & 2 & - \\
\hline \multicolumn{5}{|c|}{ Completeness of information } \\
\hline Excellent & 33 & 41.8 & 44 & 56.4 \\
\hline Very good & 24 & 30.4 & 14 & 17.9 \\
\hline Good & 15 & 19.0 & 14 & 17.9 \\
\hline Fair & 7 & 8.9 & 4 & 5.1 \\
\hline Poor & 0 & 0.0 & 2 & 2.6 \\
\hline $\mathrm{N} / \mathrm{A}$ & 0 & - & 2 & - \\
\hline \multicolumn{5}{|c|}{ Consistency of information } \\
\hline Excellent & 30 & 38.5 & 35 & 46.1 \\
\hline Very good & 24 & 30.8 & 20 & 26.3 \\
\hline Good & 17 & 21.8 & 14 & 18.4 \\
\hline Fair & 6 & 7.7 & 6 & 7.9 \\
\hline Poor & 1 & 1.3 & 1 & 1.3 \\
\hline $\mathrm{N} / \mathrm{A}$ & 1 & - & 4 & - \\
\hline
\end{tabular}

Did you feel included in the decision-making process?

\begin{tabular}{lcccc}
\hline Very included & 32 & 40.5 & 55 & 68.8 \\
\hline Somewhat included & 28 & 35.4 & 12 & 15 \\
\hline I felt neither included nor excluded & 12 & 15.2 & 6 & 7.5 \\
\hline Somewhat excluded & 3 & 3.8 & 4 & 5 \\
\hline Very excluded & 4 & 5.1 & 3 & 3.8 \\
\hline
\end{tabular}

Did you feel supported during the decision-making process?

\begin{tabular}{lllll}
\hline I felt very supported & 23 & 29.1 & 39 & 48.8 \\
\hline I felt supported & 35 & 44.3 & 27 & 33.8 \\
\hline $\begin{array}{l}\text { I felt neither overwhelmed nor } \\
\text { supported }\end{array}$ & 15 & 19 & 8 & 10 \\
\hline I felt somewhat overwhelmed & 4 & 5.1 & 5 & 6.3 \\
\hline I felt totally overwhelmed & 2 & 2.5 & 1 & 1.3 \\
\hline Did you feel you had control over the care of your family member? \\
\hline I felt I had good control & 27 & 34.2 & 45 & 56.3 \\
\hline
\end{tabular}


Table 2. (Continued.)

\begin{tabular}{lcccc}
\hline & $\begin{array}{c}\text { PRE } \\
N=79\end{array}$ & $\begin{array}{c}\text { POST } \\
N=80\end{array}$ & $\%$ \\
\hline I felt I had some control & 28 & 35.4 & 20 & 25 \\
\hline $\begin{array}{l}\text { I felt neither in control nor out of } \\
\text { control }\end{array}$ & 16 & 20.3 & 9 & 11.3 \\
\hline $\begin{array}{l}\text { I felt somewhat out of control } \\
\text { I felt really out of control }\end{array}$ & 5 & 6.3 & 4 & 5 \\
\hline $\begin{array}{l}\text { Did you have adequate time to have your concern addressed and questions } \\
\text { answered? }\end{array}$ & 3 & & & \\
\hline I had adequate time & 72 & 91.1 & 66 & 82.5 \\
\hline I could have used more time & 7 & 8.9 & 14 & 17.5 \\
\hline
\end{tabular}

$\mathrm{N} / \mathrm{A}$ responses were excluded from the frequency calculations.

ICU, intensive care unit.

(47\%) believed that the board improved communication with patients' families, only $23 \%$ disagreed. More than a third (35\%) of the clinicians agreed that patient care improved; however, $65 \%$ were either neutral or in disagreement. Even though most of the responders believed it was beneficial for the unit $(60 \%)$, the patients $(61 \%)$, and the families $(75 \%)$; a third agreed that the two-way communication boards created more work for the staff.

\section{Discussion}

Our findings suggest that the implementation of OPV, the twoway communication board, and a revamped waiting room experience enhanced communication and engagement between the family members/caregivers and the medical team. For instance, family members felt significantly more included and supported during the clinical decision-making process, which leads to a higher perception of control over medical decisions. Additionally, the three studied initiatives were well received by the family members. On the other hand, among ICU practitioners, the two-way communication board was more accepted than the OVP. More than half of the ICU practitioners believed that the two-way communication boards were beneficial for the unit and the patients. Even though half of the practitioners believed that OVP created additional work for the staff, nearly two-thirds of them also considered this initiative beneficial for the family members. Interestingly, $61.5 \%$ of the clinicians (16 out of 26 ) who believed that OVP created more work also considered it beneficial to the families.

Improving patient- and family-centered outcomes requires a multidisciplinary and coordinated effort. A multilevel approach was selected for this study due to the various facets involved, such as individual caregiver characteristics, medical team interactions, organizational logistics, and institutional policies. Each intervention aimed to improve a different level of influence. For instance, from an organizational level, we enacted an OVP; from a healthcare team level, we implemented the two-way communication boards; and from the families' environmental level, we renovated the waiting room areas. Despite the potential advantages of conducting multilevel intervention research, interpreting its results is challenging (Clauser et al., 2012; Paskett et al., 2016).

This project resulted in several steps toward improved patientand family-centered intensive care management in cancer patients. Our experience correlates with the growing interest
Table 3. ICU practitioners' perspectives about the initiatives

\begin{tabular}{|c|c|c|c|c|}
\hline & \multicolumn{2}{|c|}{$\begin{array}{l}\text { Open visitation } \\
\text { policy }\end{array}$} & \multicolumn{2}{|c|}{$\begin{array}{c}\text { Communication } \\
\text { board }\end{array}$} \\
\hline & $N=52$ & $\%$ & $N=52$ & $\%$ \\
\hline \multicolumn{5}{|c|}{ Preference for the initiative } \\
\hline Strongly agree & 9 & 17.3 & 19 & 38 \\
\hline Somewhat agree & 11 & 21.2 & 16 & 32 \\
\hline Neutral & 10 & 19.2 & 13 & 26 \\
\hline Somewhat disagree & 12 & 23.1 & 1 & 2 \\
\hline Strongly disagree & 10 & 19.2 & 1 & 2 \\
\hline $\mathrm{N} / \mathrm{A}$ & 0 & - & 2 & - \\
\hline
\end{tabular}

Communication with family improves

\begin{tabular}{lcccc}
\hline Strongly agree & 8 & 15.4 & 8 & 15.7 \\
\hline Agree & 14 & 26.9 & 16 & 31.4 \\
\hline Neutral & 14 & 26.9 & 15 & 29.4 \\
\hline Somewhat disagree & 9 & 17.3 & 8 & 15.7 \\
\hline Strongly disagree & 7 & 13.5 & 4 & 7.8 \\
\hline N/A & 0 & - & 1 & - \\
\hline
\end{tabular}

Patient care improves

\begin{tabular}{lcccc}
\hline Strongly agree & 3 & 5.8 & 7 & 13.5 \\
\hline Somewhat agree & 9 & 17.3 & 11 & 21.1 \\
\hline Neutral & 21 & 40.4 & 15 & 28.9 \\
\hline Somewhat disagree & 12 & 23.1 & 14 & 26.9 \\
\hline Strongly disagree & 7 & 13.5 & 5 & 9.6 \\
\hline
\end{tabular}

Beneficial for ICU

\begin{tabular}{lcccc}
\hline Strongly agree & 5 & 9.8 & 10 & 19.2 \\
\hline Somewhat agree & 12 & 23.5 & 21 & 40.4 \\
\hline Neutral & 13 & 25.5 & 11 & 21.2 \\
\hline Somewhat disagree & 15 & 29.4 & 7 & 13.5 \\
\hline Strongly disagree & 6 & 11.8 & 3 & 5.8 \\
\hline N/A & 1 & - & 0 & - \\
\hline
\end{tabular}

Beneficial for patients

\begin{tabular}{lcccc}
\hline Strongly agree & 9 & 17.3 & 11 & 21.6 \\
\hline Somewhat agree & 17 & 32.7 & 20 & 39.2 \\
\hline Neutral & 11 & 21.2 & 12 & 23.5 \\
\hline Somewhat disagree & 11 & 21.2 & 5 & 9.8 \\
\hline Strongly disagree & 4 & 7.7 & 3 & 5.9 \\
\hline N/A & 0 & - & 1 & -
\end{tabular}

Beneficial for families

\begin{tabular}{lcccc}
\hline Strongly agree & 14 & 26.9 & 8 & 15.7 \\
\hline Somewhat agree & 19 & 36.5 & 30 & 58.8 \\
\hline Neutral & 12 & 23.1 & 9 & 17.7 \\
\hline Somewhat disagree & 4 & 7.7 & 2 & 3.9 \\
\hline Strongly disagree & 3 & 5.8 & 2 & 3.9 \\
\hline N/A & 0 & - & 1 & - \\
\hline
\end{tabular}


Table 3. (Continued.)

\begin{tabular}{lccccc}
\hline & \multicolumn{2}{c}{$\begin{array}{c}\text { Open visitation } \\
\text { policy }\end{array}$} & & \multicolumn{2}{c}{$\begin{array}{c}\text { Communication } \\
\text { board }\end{array}$} \\
\cline { 2 - 3 } \cline { 6 - 7 } & $N=52$ & $\%$ & & $N=52$ & $\%$ \\
\hline More work for staff & & & & & \\
\hline Strongly agree & 13 & 25.5 & & 5.8 \\
\hline Somewhat agree & 13 & 25.5 & & 16 & 30.8 \\
\hline Neutral & 15 & 29.4 & 10 & 19.2 \\
\hline Somewhat disagree & 7 & 13.7 & 16 & 30.8 \\
\hline Strongly disagree & 3 & 5.9 & 7 & 13.5 \\
\hline N/A & 1 & - & 0 & - \\
\hline
\end{tabular}

$\mathrm{N} / \mathrm{A}$ responses were excluded from the frequency calculations.

ICU, intensive care unit.

and acceptance of empowering and engaging families and patients by ICU staff (Kleinpell et al., 2018; Naef et al., 2020, 2021). Despite the beneficial effects, we encountered barriers with our project. Notably, the ICU staff expressed concerns that the initiatives added additional work strain. There might be some potential explanations for the ICU staff's perception regarding the OVP. First, the use of the ICU visitation passes required the staff to keep track of whether the caregivers were authorized to enter the ICU. Second, sometimes the family members who stayed overnight would accidentally forget to hand over the pass to the following designated caregiver. Dealing with this created unplanned discussions with the family to solve the issue. Third, some caregivers gained entrance to the unit through other entrances not available to the public, which could have made the practitioners feel that their efforts to provide a structured OVP were futile. This phenomenon is not unique to our project. Previous studies have reported the nursing staff concerns that more liberal visitation policies may interfere with their ability to provide excellent patient care (Berti et al., 2007; Kozub et al., 2017). However, ICUs with open visitation reported that families were highly satisfied with the policy (Soury-Lavergne et al., 2012; Chapman et al., 2016). Physicians and nurses in open visitation ICUs tended to view the policy positively as well (Giannini et al., 2013; Chapman et al., 2016).

We also faced difficulties implementing the two-way communication boards. The most commonly reported difficulty by the nursing staff was when other patients occasionally required their attention during rounds, precluding the nurse from writing down that particular patient's goal or taking the extra time to talk to the team and address the family. Despite these issues, family members felt more included in the discussions, which is consistent with the literature. Pronovost et al. (2003) carried out a prospective study in which the implementation of daily goal forms resulted in all staff having a better understanding of the goals for individual patients and improved information traffic and communication between families and staff. Additionally, another study reported that implementing ICU daily goal boards decreased the hospital length of stay and reduced errors of omission (Binnekade et al., 2010).

In light of the obstacles we faced, there is a need to promote the higher acceptance of patient- and family-centered outcomes among the ICU staff. Addressing logistical and operational hurdles expressed by the staff should be a priority. Failing to show willingness to hear their input to improve the initiatives' workflow could lead to a loss of support from the staff. Another potential action that should be considered is conducting educational sessions about patient-centered outcomes, as this seems to be a viable alternative to reach wider acceptance among the practitioners (Coyne and Dieperink, 2017; Nguyen et al., 2017).

Other initiatives to improve patients' and families' experience in the critical care-related facilities are currently being analyzed before introduction in our unit. For instance, specialized care packages could be provided to the family/caregiver when transitioning to comfort care. This gesture can be used to educate and offer a more empathetic environment for patients, families, and staff during the bereavement process (Oliver et al., 2010). Another strategy is introducing the ICU diary to help support patients and families during their ICU stay. The ICU diary can provide resources for caregiver support and the prevention and management of ICU delirium (Rogan et al., 2020). Furthermore, the implementation of ICU diaries could also nurture communication and journaling tools that facilitate mental and physical wellness. Future potential interventions must integrate family-centered outcomes with new technologies such as developing a mobile device application that allows easy access to technological education and frequent ICU questions posed by patients and their caregivers. Due to the wide variability between the acceptance and integration of various initiatives, further research on different strategies to successfully increase patient and family engagement is essential.

The present study has several limitations. First, we encountered resistance to cultural change when staff put up barriers to engagement with two-way communication boards. Second, the multilevel implementation of concurrent patient-centered interventions at once made it difficult to isolate the potential beneficial effects of any single measure. Our study could have benefitted from a multilevel regression analysis that could, in part, isolate the effect of each intervention. Third, due to the nature of the study, different families were surveyed before and after the program was enacted. Thus, differences found between the PRE and POST surveys could have arisen from individual inherent factors of the two groups of respondents rather than being a product of the interventions. Fourth, our institution already had high interaction between patient families and ICU practitioners. Thus, this high baseline engagement could have skewed the observed effect. Therefore, our findings should be cautiously interpreted. For instance, the improvement in family communication and engagement and the higher work burden expressed by practitioners in our study might not be similar if the interventions were implemented in different settings such as community nonspecialized cancer centers. Further research should address these concerns.

\section{Conclusions}

Our project effectively promoted patient- and family-centered care. The families expressed satisfaction with the communication of information and the decision-making process. Even though more than half of the practitioners agreed that an OVP was beneficial for families, there was a concern that it could create an additional burden to the staff. Practitioners were generally against implementing an OVP and did not believe it would help in patient care. The majority of practitioners supported the use of the two-way communication board which helped transfer information to families and improved their satisfaction. Finally, the added features in the ICU waiting room led to positive changes in family satisfaction. However, due to our limitations, further 
research is needed to understand whether making this project universal or introducing additional novel practices would significantly benefit patients and families in the ICU.

Supplementary material. The supplementary material for this article can be found at https://doi.org/10.1017/S1478951521001838.

Acknowledgments. We appreciate the contributions of Mary Ann Oler, education program coordinator of the Department of Critical Care Medicine at The University of Texas MD Anderson Cancer Center, and Tamara K. Locke from the office of Scientific Publications at The University of Texas MD Anderson Cancer Center for their valuable editorial contributions. Part of this work was presented as an abstract in the $49^{\text {th }}$ Annual Critical Care Congress of the Society of Critical Care Medicine, 16-19 ${ }^{\text {th }}$ February 2020.

Funding. Supported by the NIH/NCI award number P30CA016672. Dr. Nates' work is supported by the George Sweeney Fellowship, The University of Texas MD Anderson Cancer Center Grant Resources.

Conflict of interest. The authors declare no conflict of interest directly applicable to this research.

\section{References}

A Self-Assessment Inventory (2019) Institute for Patient- and Family-Centered Care: Patient- and Family- Centered Adult Intensive Care. 2019. Available at: https://www.ipfcc.org/resources/assessment.html (accessed June 2021).

Adams S, Herrera A, Miller L, et al. (2011) Visitation in the intensive care unit. Critical Care Nursing Quarterly 34, 3-10.

Azoulay É, Curtis JR and Kentish-Barnes N (2021) Ten reasons for focusing on the care we provide for family members of critically ill patients with COVID-19. Intensive Care Medicine 47, 230-233.

Berti D, Ferdinande P and Moons P (2007) Beliefs and attitudes of intensive care nurses toward visits and open visiting policy. Intensive Care Medicine 33, 1060-1065.

Binnekade JM, Brunsveld A, Arbous S, et al. (2010) Implementation of daily goals in the ICU reduces length of ICU stay and errors of omission in patient care. Critical Care 14, P466.

Bishop SM, Walker MD and Mark Spivak I (2013) Family presence in the adult burn intensive care unit during dressing changes. Critical Care Nursing 33, 14-24.

Cacioppo JT, Hawkley LC, Norman GJ, et al. (2011) Social isolation. Annals of the New York Academy of Sciences 1231, 17-22.

Chapman DK, Collingridge DS, Mitchell LA, et al. (2016) Satisfaction with elimination of all visitation restrictions in a mixed-profile intensive care unit. American Journal of Critical Care 25, 46-50.

Clauser SB, Taplin SH, Foster MK, et al. (2012) Multilevel intervention research: Lessons learned and pathways forward. Journal of the National Cancer Institute. Monographs 2012, 127-133.

Coyne E and Dieperink KB (2017) A qualitative exploration of oncology nurses' family assessment practices in Denmark and Australia. Support Care Cancer 25, 559-566.

Cuenca JA, Laserna A, Reyes MP, et al. (2020) Critical care admission of an HIV patient with diabetic ketoacidosis secondary to pembrolizumab. Case Reports Critical Care 2020, 8671530.

Davidson JE, Aslakson RA, Long AC, et al. (2017) Guidelines for family-centered care in the neonatal, pediatric, and adult ICU. Critical Care Medicine 45, 103-128.

Deitrick L, Ray D, Stern G, et al. (2005) Evaluation and recommendations from a study of a critical-care waiting room. Journal for Healthcare Quality 27, 17-25.

Dupree E, Fritz-Campiz A and Musheno D (2014) A new approach to preventing falls with injuries. Journal of Nursing Care Quality 29, 99-102.
Fumagalli S, Boncinelli L, Lo Nostro A, et al. (2006) Reduced cardiocirculatory complications with unrestrictive visiting policy in an intensive care unit: Results from a pilot, randomized trial. Circulation 113, 946-952.

Giannini A, Miccinesi G, Prandi E, et al. (2013) Partial liberalization of visiting policies and ICU staff: A before-and-after study. Intensive Care Medicine 39, 2180-2187.

Girgis A, Lambert S, Johnson C, et al. (2013) Physical, psychosocial, relationship, and economic burden of caring for people with cancer: A review. Journal of Oncology Practice 9, 197-202.

Gutierrez C, McEvoy C, Mead E, et al. (2018) Management of the critically Ill adult chimeric antigen receptor- $\mathrm{T}$ cell therapy patient: A critical care perspective. Critical Care Medicine 46, 1402-1410.

Karlsson C, Tisell A, Engstrom A, et al. (2011) Family members' satisfaction with critical care: A pilot study. Nursing Critical Care 16, 11-18.

Kleinpell R, Heyland DK, Lipman J, et al. (2018) Patient and family engagement in the ICU: Report from the task force of the world federation of societies of intensive and critical care medicine. Journal Critical Care $\mathbf{4 8}$ 251-256.

Kleinpell R, Zimmerman J, Vermoch KL, et al. (2019) Promoting family engagement in the ICU: Experience from a national collaborative of 63 ICUs*. Critical Care Medicine 47, 1692-1698.

Kozub E, Scheler S, Necoechea G, et al. (2017) Improving nurse satisfaction with open visitation in an adult intensive care unit. Critical Care Nursing Quarterly 40, 144-154.

Lee HW, Park Y, Jang EJ, et al. (2019) Intensive care unit length of stay is reduced by protocolized family support intervention: A systematic review and meta-analysis. Intensive Care Medicine 45, 1072-1081.

Liu V, Read J, Scruth E, et al. (2013) Visitation policies and practices in US ICUs. Critical Care 17, R71.

Naef R, Massarotto P and Petry H (2020) Family and health professional experience with a nurse-led family support intervention in ICU: A qualitative evaluation study. Intensive Critical Care Nurses 61, 102916.

Naef R, von Felten S, Petry H, et al. (2021) Impact of a nurse-led family support intervention on family members' satisfaction with intensive care and psychological wellbeing: A mixed-methods evaluation. Australian Critical Care 34, 594-603.

Nguyen TK, Bauman GS, Watling CJ, et al. (2017) Patient- and family-centered care: A qualitative exploration of oncologist perspectives. Support Care Cancer 25, 213-219.

Oliver MA, Hillock S, Moore C, et al. (2010) Comfort care packs: A little bit of hospice in hospital? International Journal of Palliative Nursing 16, 511515.

Paskett E, Thompson B, Ammerman AS, et al. (2016) Multilevel interventions to address health disparities show promise in improving population health. Health Affairs 35, 1429-1434.

Pronovost P, Berenholtz S, Dorman T, et al. (2003) Improving communication in the ICU using daily goals. Journal of Critical Care 18, 71-75.

Rogan J, Zielke M, Drumright K, et al. (2020) Institutional challenges and solutions to evidence-based, patient-centered practice: Implementing ICU diaries. Critical Care Nurses 40, 47-56.

Soury-Lavergne A, Hauchard I, Dray S, et al. (2012) Survey of caregiver opinions on the practicalities of family-centred care in intensive care units. Journal of Clinical Nursing 21, 1060-1067.

Sun V, Raz DJ and Kim JY (2019) Caring for the informal cancer caregiver. Current Opinion in Supportive and Palliative Care 13, 238-242.

Thompson DR, Hamilton DK, Cadenhead CD, et al. (2012) Guidelines for intensive care unit design. Critical Care Medicine 40, 1586-1600.

Wall RJ, Engelberg RA, Downey L, et al. (2007) Refinement, scoring, and validation of the family satisfaction in the intensive care unit (FS-ICU) survey* Critical Care Medicine 35, 271-279.

Wallace SK, Rathi NK, Waller DK, et al. (2016) Two decades of ICU utilization and hospital outcomes in a comprehensive cancer center. Critical Care Medicine 44, 926-933. 